\title{
Momentum transfer at the high-latitude magnetopause and boundary layers
}

\author{
E. J. Lund ${ }^{1}$, C. J. Farrugia ${ }^{1}$, and P. E. Sandholt ${ }^{2}$ \\ ${ }^{1}$ Space Science Center, University of New Hampshire, Durham, New Hampshire, USA \\ ${ }^{2}$ Department of Physics, University of Oslo, Oslo, Norway
}

Received: 7 April 2008 - Revised: 10 June 2008 - Accepted: 27 June 2008 - Published: 13 August 2008

\begin{abstract}
How and where momentum is transferred from the solar wind to the magnetosphere and ionosphere is one of the key problems of space physics. Much of this transfer occurs through direct reconnection on the dayside, particularly when the IMF is southward. However, momentum transfer also occurs at higher latitudes via Alfvén waves on old open field lines, even for southward IMF. This momentum is transferred to the ionosphere via field-aligned currents (FACs), and the flow channel associated with these FACs produces a Hall current which causes magnetic variations at high latitude (the Svalgaard-Mansurov effect). We show examples where such momentum transfer is observed with multiple spacecraft and ground-based instruments.
\end{abstract}

Keywords. Magnetospheric physics (Current systems; Magnetopause, cusp, and boundary layers; Magnetosphereionosphere interactions)

\section{Introduction}

Large-scale field-aligned currents (FACs) transmit stresses originating at the magnetopause and its boundary layers throughout the magnetosphere-ionosphere system. Their existence was established a long time ago from the magnetic deflections registered by polar-orbiting spacecraft (Zmuda et al., 1966; Armstrong and Zmuda, 1973). That FACs are a quasi-permanent feature of the magnetosphere was determined from the extensive statistics using measurements made by the Triad spacecraft by Iijima and Potemra (1976) and are subject to variations in intensity related to the IMF direction (see Cowley, 2000, for a review). These are called Region 1 (higher latitude) and 2 currents (R1 and R2) and they form two rings of currents next to each other.

Correspondence to: E. J. Lund

(eric.lund@unh.edu)
Using 47 passes of the Dynamics Explorer spacecraft, Taguchi et al. (1993) established conclusively the presence of a separate pair of FACs - the cusp/cleft currents - lying poleward of the R1 and R2 currents. Their position and direction (into or out of the ionosphere) is governed by the polarity of the IMF east-west component, $B_{y}$. Thus, for IMF $B_{y}>0$ $\left(B_{y}<0\right)$, they lie on the prenoon (postnoon) side and are such that the current in the higher latitude component, which we call hereinafter $\mathrm{C}$, flows out of (into) the ionosphere, and that in the lower-latitude component $\mathrm{C} 2$ flows into (out of) the ionosphere. Thus in both cases the current in $\mathrm{C} 2$ flows in the same direction as that in $\mathrm{R} 1$ and the current in $\mathrm{C} 1$ flows in the same direction as that in R2. These cusp currents had been predicted on theoretical grounds (Lee et al., 1985) based on considerations of reconnection at a magnetopause when it is a rotational discontinuity. Taguchi et al. (1993) postulated steady reconnection as origin for these currents.

Confirmation of most aspects of Taguchi et al.'s scenario has come from observations over the last decade. In a fortuitous triple conjunction between Cluster, FAST, and Svalbard, Farrugia et al. (2004a) found Alfvénic flow bursts at Cluster, which they interpreted as signatures of FTEs, embedded in a FAC system observed at FAST at $\sim 900 \mathrm{~km}$ altitude and mapping to a transient flow channel observed in the ionosphere with the Søndrestrøm radar. A series of case studies combining Polar and/or DMSP data with optical data from Ny Ålesund (Farrugia et al., 2003; Sandholt et al., 2004, 2006; Sandholt and Farrugia, 2007a) linked the FTE-like signatures and precipitating particles to poleward moving auroral forms (PMAFs) associated with this flow channel. These works demonstrate that momentum transfer is maintained on previously reconnected field lines which are connected to a dynamo region in the magnetopause boundary layer tailward of the cusp (the high-latitude boundary layer, HBL). This mechanism suggests an additional source of the magnetic field deflections at high latitude for nonzero IMF $B_{y}$ known as the Svalgaard-Mansurov effect (Svalgaard, 1968;

Published by Copernicus Publications on behalf of the European Geosciences Union. 


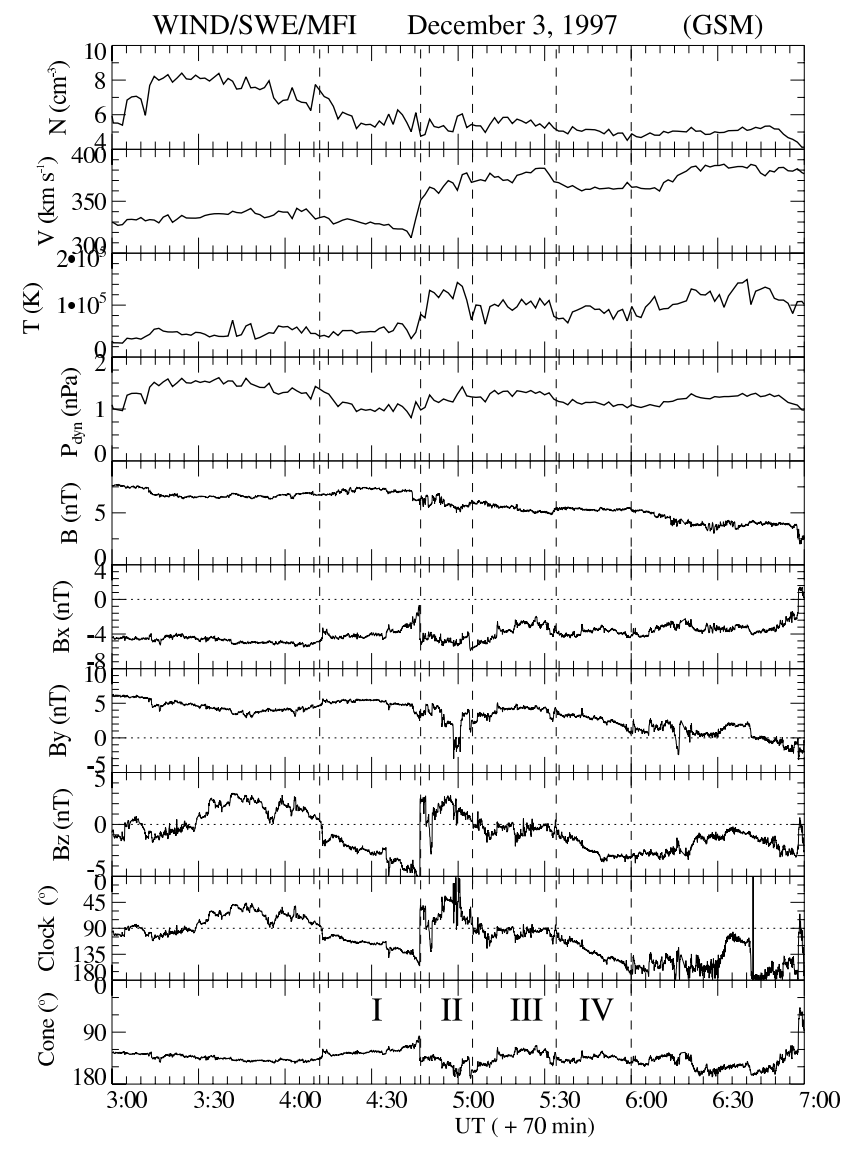

Fig. 1. Interplanetary conditions as observed by Wind on 3 December 1997. The UT reflects the estimated 70-min lag from Wind to the magnetopause. Top to bottom: Solar wind density, velocity, temperature, and dynamic pressure; total interplanetary magnetic field, its GSM components, clock angle (azimuth in $Y Z_{\mathrm{GSM}}$ plane), and cone angle (angle from $X_{\mathrm{GSM}}$ direction).

Mansurov, 1969). Our observations extend the interpretation of Taguchi et al. (1993) in that they focus on temporal variability in these currents and thus relate them to transient, rather than steady, reconnection. Specifically, these events have been linked to flux transfer events (FTEs; Russell and Elphic, 1978), and they agree with other observations of FTEs at high latitudes (Thompson et al., 2004). The observations cover cases with both signs of $B_{y}$, and the pattern has been consistent: the $\mathrm{C} 1 / \mathrm{C} 2$ currents and flow channels occur prenoon (postnoon) for positive (negative) $B_{y}$ (all these observations are from the Northern Hemisphere).

In this paper we will focus on two examples of this phenomenon: 3 December 1997 and 21 January 2001. In presenting these examples, we follow a long tradition in the field of solar wind-magnetosphere-ionosphere coupling which has been overlooked in recent years, namely, momentum coupling via the dynamo region in the HBL (Cowley, 1981; Stern, 1984; Siscoe et al., 1991, 2000; Taguchi et al., 1993).

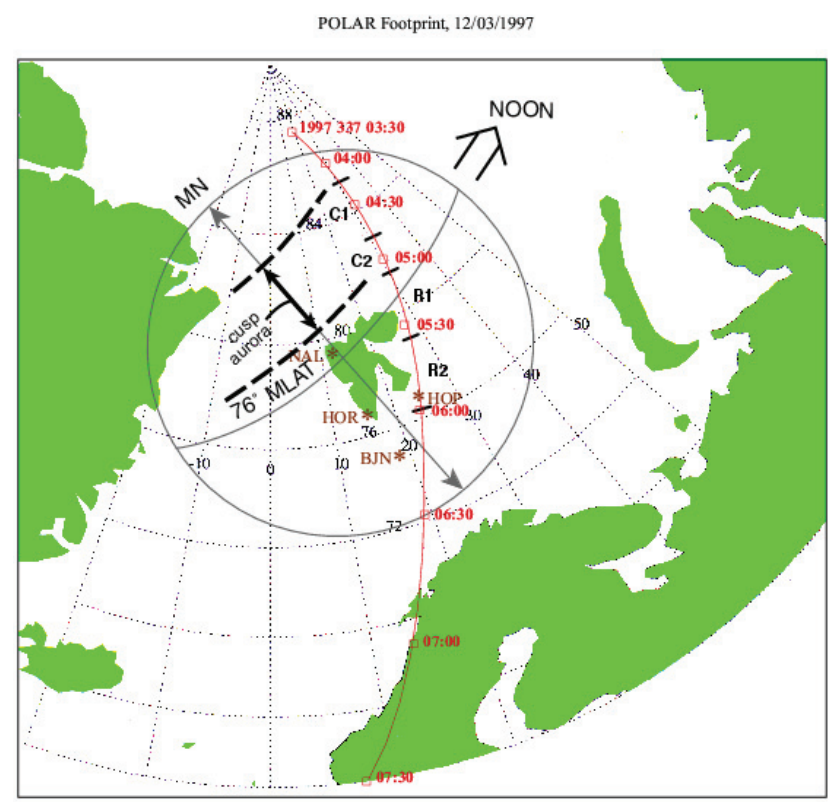

Fig. 2. Map showing the trajectory of Polar's magnetic footpoint relative to observatories around Svalbard. Also shown is the approximate region where cusp aurora was observed from $\mathrm{Ny}$ Ålesund.

We present the data in the next two sections, discuss our interpretation of the data in Sect. 4, and give our concluding remarks in Sect. 5.

\section{December 1997}

The interplanetary conditions observed by Wind (Lepping et al., 1995; Ogilvie et al., 1995) during this event, which was first examined by Farrugia et al. (2003), are shown in Fig. 1. The UTs in the figure have been modified to take into account the estimated 70-min propagation delay between Wind and the magnetopause. The labels I-IV in the figure indicate times when, as will be shown below, the Polar spacecraft passed through various large-scale FACs. The IMF $B_{z}$ turned southward at the start of interval I, turned northward again at a field and flow discontinuity during interval II, was slightly negative during interval III, and became increasingly negative during interval IV. Note that IMF conditions were similar during intervals I and IV. Apart from a brief excursion to near zero at about 05:00 UT (during interval II), $B_{y}$ was positive during this period, and for most of this time $B_{y}>\left|B_{z}\right|$.

Figure 2 shows the geographical background for this event. The red track is the magnetic footpoint of Polar, which passed to the east of Svalbard with closest approach near 05:30 UT. Asterisks mark the locations of several ground stations in the vicinity, of which the ground optical site NAL (Ny Ålesund) is of greatest interest here. The stations and the Polar spacecraft were all in the prenoon sector, with the main 


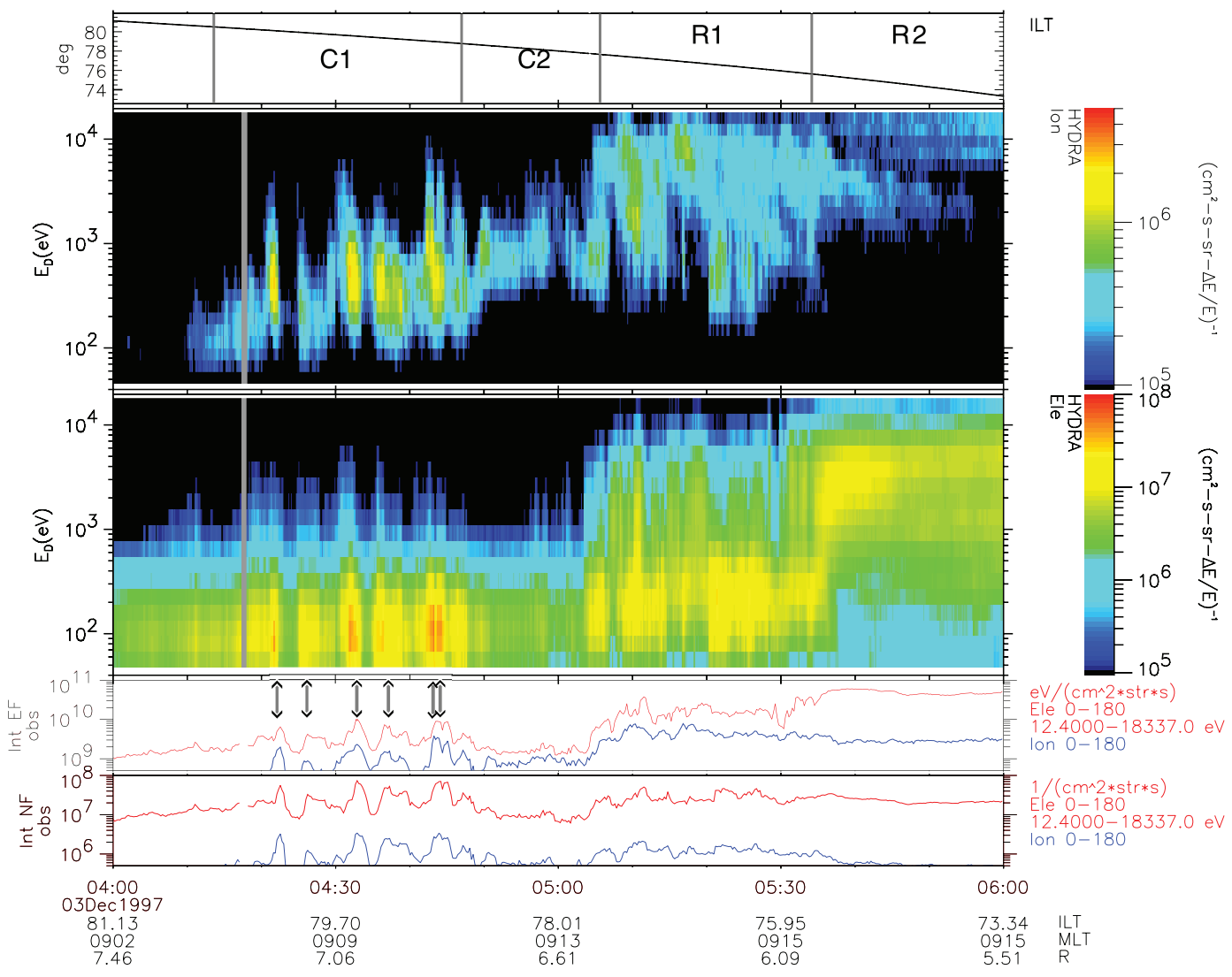

Fig. 3. Data from the Polar spacecraft pass through the region of cusp aurora. Top to bottom: invariant latitude; ion and electron energy spectrograms; integrated energy and number fluxes for electrons (red) and ions (blue).

auroral activity located poleward of Ny Ålesund. Although optical data are not available before 05:15 UT, meridian scanning photometer and all-sky camera data taken during the interval marked IV in Fig. 1 show a series of quasi-periodic auroral intensifications at intervals of 7-8 min to the north of Ny Ålesund, in the same latitude range that Polar traversed during interval I. Since intervals I and IV were under similar IMF conditions, it is reasonable to assume that similar auroral activity was occurring at these latitudes during interval I. The large-scale FACs encountered by Polar are marked along its trajectory. The identifications are based on the measured deflections and fluctuations of the magnetic field (see Farrugia et al., 2003, Fig. 3).

Polar particle data (HYDRA; Scudder et al., 1995) for the interval 04:00-06:00 UT are shown in Fig. 3. The large-scale FAC identifications are marked in the top panel. Several bursts of low energy particles $(\sim 300 \mathrm{eV}$ ions and $\sim 100 \mathrm{eV}$ electrons) are visible in the time period corresponding to interval I of Fig. 1. These signatures are consistent with FTEs originating at a reconnection line tilted with respect to the geomagnetic equator, as appropriate for a significant IMF $B_{y}$. As will be explained below, we infer the existence of an upward FAC in this region. Comparison with later inter- vals leads us to identify this region as the $\mathrm{C} 1$ current. As Polar moved equatorward into a region of downward FAC which we identify as the $\mathrm{C} 2$ current, these temporally varying structures ceased; however, since the IMF $B_{z}$ turned positive around this time we cannot determine whether the change is due to the change in current or the change in IMF. We distinguish $\mathrm{C} 2$ from R1, which has the same sign, by (1) the convection reversal separating them and (2) the appearance of plasma sheet particles in the $\mathrm{R} 1$ current. The directions of the four current sheets agree with the results of Taguchi et al. (1993).

In Fig. 4 we show an expanded view of Polar magnetic field (Russell et al., 1995) and plasma moments from the interval marked I in Fig. 1, during which Polar was in the $\mathrm{C} 1$ FAC. The trend in the observed $B_{y}$ (second panel) reveals the presence of an upward FAC. Here we see several transient bursts in the ion bulk velocity, each of which is accompanied by a negative deflection in $v_{z}$, a reduction in the magnetic field magnitude, and a positive deflection in $B_{z}$. The magnetic field fluctuations are due to transient diamagnetic currents transverse to $\boldsymbol{B}$. The vertical dash-dot lines passing through local maxima in the density mark several examples in the figure. The flow bursts at Polar (04:10-04:50 UT; 


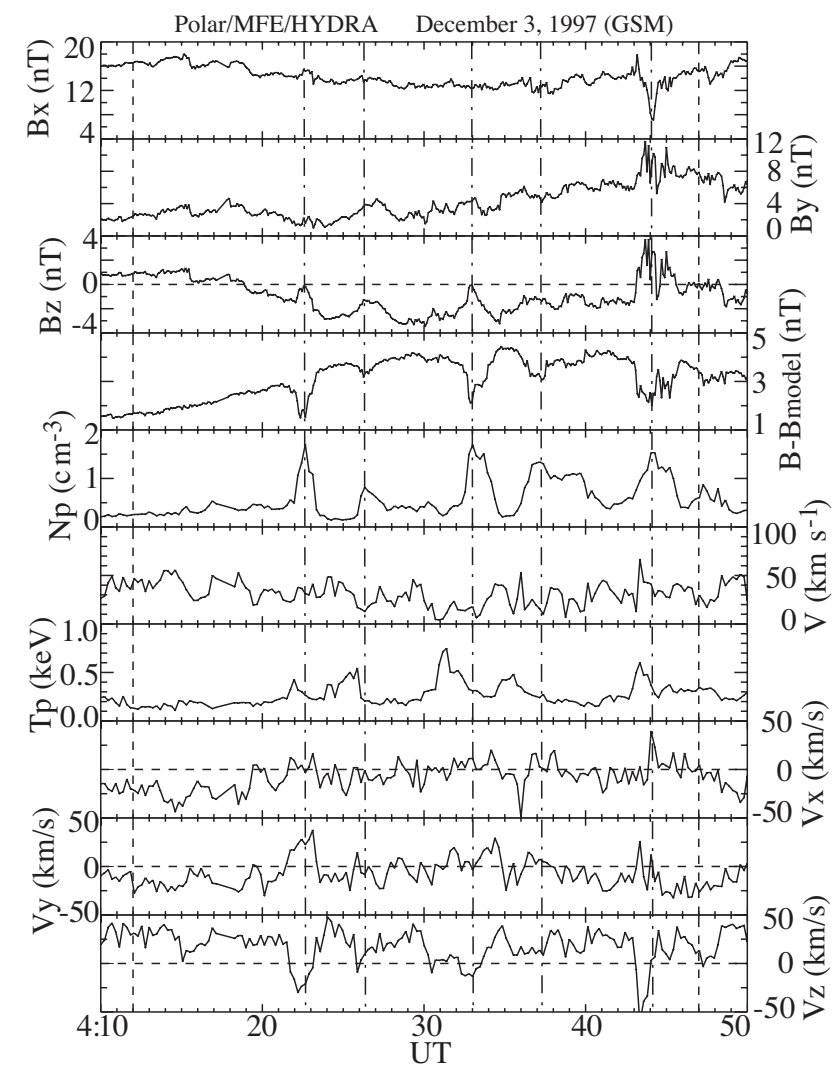

Fig. 4. Expanded view of Polar magnetic field and plasma moments from the interval marked I in Fig. 1. Top to bottom: Magnetic field components; magnetic field magnitude (IGRF model subtracted); proton density, bulk speed, temperature, and velocity components. Vertical dash-dot lines indicate flow bursts which are consistent with FTE signatures.

$\sim 79^{\circ}$ magnetic latitude, MLAT) occurred at a time when a series of poleward propagating magnetic impulse events (MIEs) was observed in the same MLT sector by the IMAGE Svalbard magnetometer chain $\left(71-76^{\circ}\right)$. The poleward propagation of the IMAGE disturbances (MIEs) corresponds to the poleward propagation of the convection channel and Hall current associated with ionospheric current closure of FACs in newly-reconnected flux tubes as envisaged, for example, by Southwood (1987). The ions in these flow bursts are of typical magnetosheath energies (a few hundred $\mathrm{eV}$ ) and were accompanied by field-aligned electrons (not shown). The positive $v_{z}$ background flow on which these flow bursts are superimposed is characteristic of mirroring ions in the mantle (Rosenbauer et al., 1975), while the flow bursts themselves have negative $v_{z}$, consistent with injections at high latitude on old open field lines (reconnected in the past) in the mantle. The temperature and density profiles suggest two components with different injection latitudes: a warmer, less dense component injected behind the cusp, followed by a cooler,

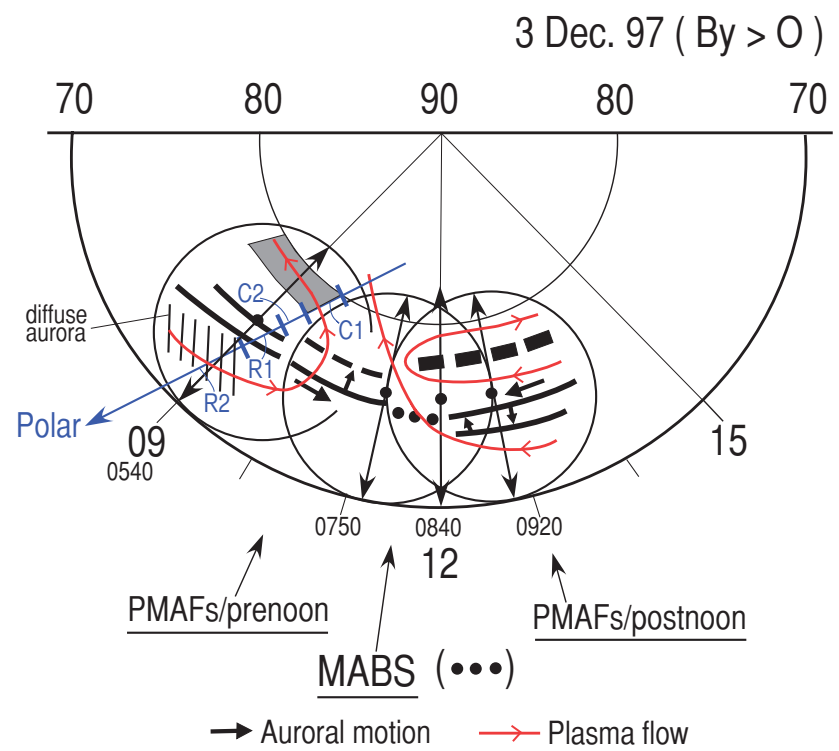

Fig. 5. Schematic of the Polar footpoint track in the context of aurora and plasma convection in MLT/MLAT coordinates during the interval 05:40-09:30 UT on 3 December 1997. Approximate fields of view (assuming a typical $250 \mathrm{~km}$ altitude for the $630.0 \mathrm{~nm}$ emissions) of the MSP at Ny Ålesund are indicated by double-arrowed meridional lines for the times 05:40 UT, 07:50 UT, and 09:20 UT; circles mark the all sky camera fields of view for the same times. Auroral motions are indicated by arrows attached to the respective forms. Plasma convection streamlines are marked red. The shaded sector marks the plasma convection channel associated with the $\mathrm{C} 1$ C2 field-aligned currents.

denser component injected closer to the central cusp (Smith, 1994). Thus the flow bursts have some of the characteristics of flux transfer events (FTEs) (Russell and Elphic, 1978). These observations suggest that time variations in the reconnection rate may be important in the $\mathrm{C} 1$ current region.

Figure 5 is a schematic overview of the observations. Circles and double-headed arrows show the fields of view in MLT-MLAT of the all-sky camera and meridian scanning photometer, respectively, at 05:40, 07:50, and 09:20 UT (a source altitude of $250 \mathrm{~km}$ for the $630 \mathrm{~nm}$ emissions is assumed). The discrete auroral forms moved as indicated by the black arrows, while the background plasma flow pattern derived from SuperDARN radars followed the red arrowed lines. A finer structure of poleward propagating plasma convection events superimposed on this average pattern can be derived from ground magnetometers in the Svalbard IMAGE chain. As mentioned above, a series of such events was observed at IMAGE in the interval 04:10-04:50 UT, similar to that described for $B_{y}>0$ /prenoon conditions in Fig. 12 of Øieroset et al. (1997). Note the different evolution of PMAFs in the prenoon and postnoon sectors, a point on which we will elaborate further in Sect. 4. The track of Polar's ionospheric footpoint is shown in blue. The $\mathrm{C} 1$ and $\mathrm{C} 2 \mathrm{FACs}$ 


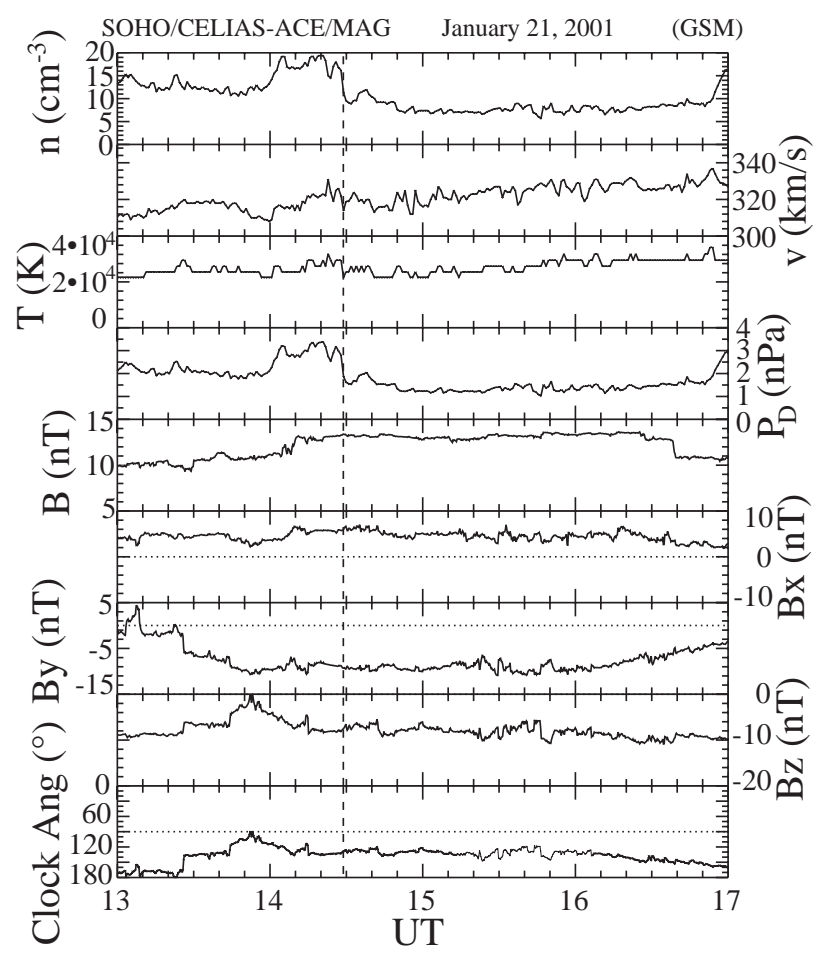

Fig. 6. Solar wind from SOHO/CELIAS and IMF from ACE on 21 January 2001. The time refers to the ACE spacecraft and does not include a delay of $75 \mathrm{~min}$ (confirmed by observations as discussed in the text). Top to bottom: Solar wind density, velocity, temperature, and dynamic pressure; total magnetic field, its GSM components, and clock angle.

were in the shaded region near $80^{\circ}$ MLAT; they occur only in the prenoon sector. The region marked MABS in the figure is an MLT band near local noon with attenuated emission intensity.

\section{January 2001}

During the second event, which was first examined by Farrugia et al. (2004a), the IMF was much more steady with $B_{y}<0, B_{z}<0$, and $B_{y} \sim B_{z}$, as can be seen in the interplanetary data shown in Fig. 6 . This is the opposite $B_{y}$ polarity to the first event. Here the time shown is at ACE, where the magnetometer measurements (Smith et al., 1998) were made. We show plasma data from SOHO/CELIAS (Hovestadt et al., 1995), shifted to ACE times, because the corresponding ACE plasma data are considered unreliable during this interval. Estimated lag time from ACE to the magnetopause is $75 \mathrm{~min}$; we can confirm this timing thanks to the abrupt drop in solar wind density, and therefore dynamic pressure, at the time ( 14:28 UT) marked with the vertical dashed line.

Figure 7 shows the footpoints (magnetically mapped to $100 \mathrm{~km}$ via the Tsyganenko, 1989, model) of the Cluster

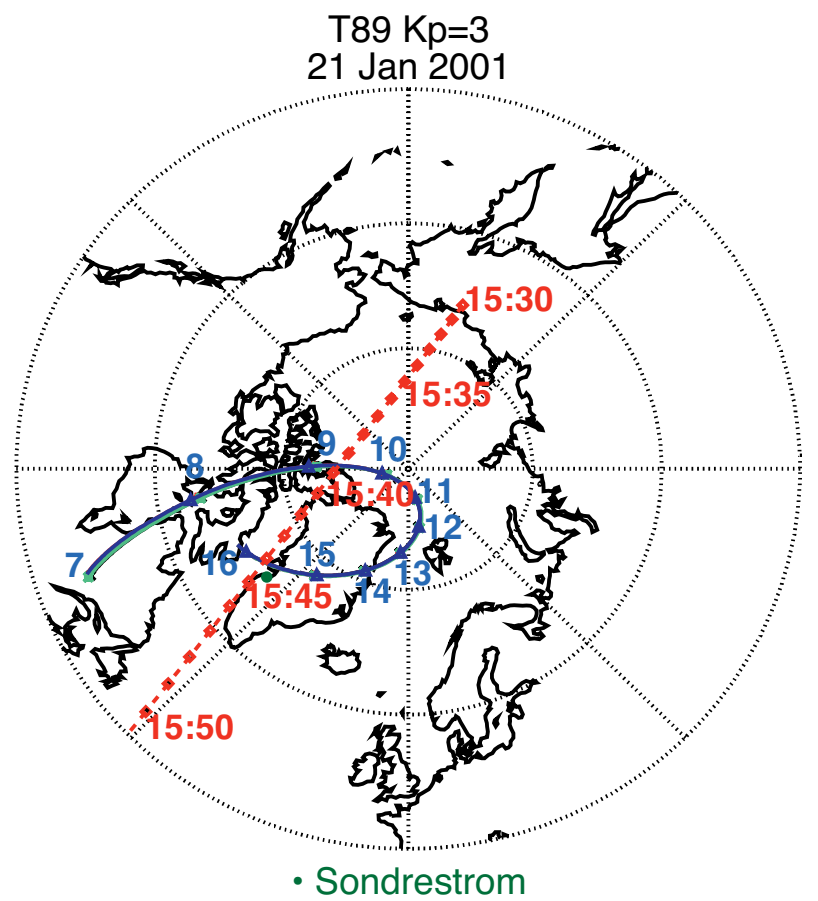

Fig. 7. Ionospheric footpoints of FAST (red) and Cluster (blue) relative to Søndrestrøm.

(blue) and FAST (red) spacecraft. A magnetic conjunction occurs where the trajectories cross at about 15:45 UT, which is near the time when the dynamic pressure drop arrives at the magnetopause. The conjunction maps to near the location of the Søndrestrøm radar (green dot). At the time of conjunction Søndrestrøm was at about 13:00 MLT at the openclosed field line boundary (Farrugia et al., 2004a). The radar at Søndrestrøm observed a transient flow channel around the time of conjunction, with strong $\sim 2 \mathrm{~km} / \mathrm{s}$ antisunward flow just poleward of the convection reversal (see Farrugia et al., 2004a, Fig. 13). Since the IMF $B_{y}$ is negative here, in contrast to the 3 December 1997 event, the C1/C2 currents and associated flow channels should be postnoon, which is where the observations took place.

In Fig. 8 we show particle spectrograms from FAST during the conjunction. FAST was moving equatorward through the cusp at about $900 \mathrm{~km}$ altitude. A key feature is the stepped cusp ion dispersion (third panel) located poleward of the open-closed field line boundary. The existence of multiple steps in the ion velocity dispersion is frequently taken as evidence of impulsive reconnection along the dayside magnetopause (e.g. Lockwood and Smith, 1992), although it is sometimes interpreted as evidence of multiple reconnection sites (e.g. Trattner et al., 1999). Stepped cusp ion precipitation is also associated with PMAFs (Farrugia et al., 1998). As we will show below, there is significant evidence of timevarying reconnection during this event. 


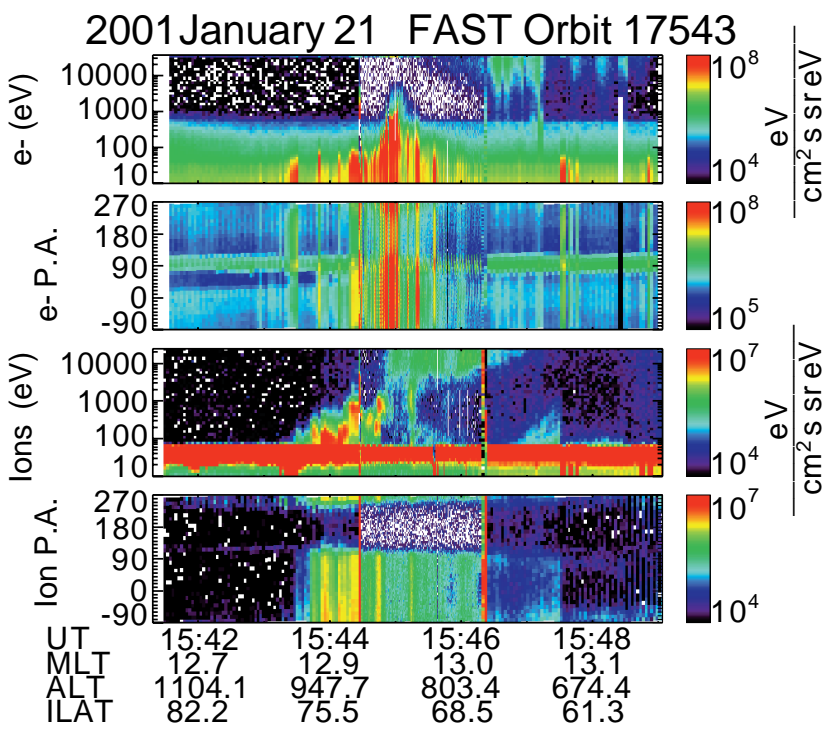

Fig. 8. Spectrograms of particle data from the FAST spacecraft as it passes through the cusp. Top to bottom: electron energy, electron pitch angle, ion energy, and ion pitch angle.

Among the signatures of time-varying reconnection we see is repeated poleward moving flow bursts in beams 5-7 of the Stokkseyri SuperDARN radar (Fig. 9), which looks toward Greenland. The earliest such flows begin around 14:40, but they become particularly intense at about 15:35. Previously reported observations have demonstrated an association between these poleward moving radar auroral forms and FTEs (Wild et al., 2001, and references therein).

Figure 10 shows an overview of the data from Cluster 1 from 13:00 to 18:00. Cluster made several excursions into the cusp between 14:00 and 15:00, as can be seen from the diamagnetic features in $|B|$. Once the dynamic pressure decrease hit the magnetopause around 15:35 (as can be seen from the sudden density drop at Cluster), Cluster entered a highly dynamic region with large amplitude fluctuations in both $\boldsymbol{B}$ and the ion flow velocity $\boldsymbol{v}$, the latter reaching a substantial fraction of the solar wind speed $\left(320 \mathrm{~km} \mathrm{~s}^{-1}\right)$. At this time Cluster was poleward of the cusp: the background field had $B_{x}>0$ and $B_{z}<0$.

To see these fluctuations better, we expand the interval between the vertical dashed lines in Fig. 11. At this scale it is clear that the fluctuations in $\boldsymbol{B}$ and $\boldsymbol{v}$ are correlated, component by component. Eight examples of these flow bursts, which are consistent with FTEs, are shown in the figure, the first coinciding with the arrival of the dynamic pressure decrease at the magnetopause. Each component of $\boldsymbol{B}$ and $\boldsymbol{v}$ separately satisfies the Walén relation (Sonnerup et al., 1981), demonstrating that these flow bursts are Alfvénic. Finally, in the bottom panel of Fig. 11 we show the east-west magnetic field (IGRF subtracted) as observed by FAST during the interval 15:43-15:46. From the FAST magnetometer data we infer the existence of two FAC systems: the C1/C2 system in which the flow bursts are embedded, and the R1/R2 system located equatorward of the $\mathrm{C} 1 / \mathrm{C} 2$ system, with $\mathrm{R} 1$ and $\mathrm{C} 2$ having the same sign. The $\mathrm{C} 1$ current flows into the ionosphere, as indicated by the sign of the magnetic deflection. During its traversal of C1, FAST observed mantle precipitation, as expected for the location of Cluster 1 (Rosenbauer et al., 1975); thus these flux tubes have been opened at some point in the past, i.e. they are old open flux tubes. We infer that the FAC due to these FTEs is driving the intermittent flows we observe in the radar data, and therefore infer that the high-latitude boundary layer (HBL) acts as a dynamo $(\boldsymbol{j} \cdot \boldsymbol{E}<0)$. This mode of momentum transfer from magnetosphere to ionosphere is not due to the $\boldsymbol{j} \times \boldsymbol{B}$ force.

\section{Discussion}

The two events we have shown here, as well as several other case studies (Provan et al., 2002; Sandholt et al., 2004, 2006; Sandholt and Farrugia, 2007a), build evidence for the proposition that momentum transfer from the solar wind to the ionosphere is not restricted to newly reconnected flux tubes, but also continues on previously reconnected flux tubes downstream of the cusp. Field line stresses and FTEs give rise to an FAC system, whose location relative to noon depends on the IMF $B_{y}$, poleward of the auroral Birkeland currents (Taguchi et al., 1993). These FACs couple to a flow channel poleward of the convection reversal boundary. Theoretical models of ionospheric convection under strong $B_{y}$ have hitherto not taken into account this flow channel and its associated electrodynamics. This flow channel cannot have been driven by the $\boldsymbol{j} \times \boldsymbol{B}$ force on newly opened field lines; instead it is connected to the boundary layer dynamo region threaded by old open field lines tailward of the cusp. Any model of solar wind-magnetosphere-ionosphere momentum transfer which depends exclusively on the $\boldsymbol{j} \times \boldsymbol{B}$ force on newly opened field lines is therefore incomplete.

Our work confirms and extends the work of Thompson et al. (2004), who noted a specific magnetic field signature in Cluster data, namely a reversal in $B_{z}$, when Cluster was downstream of the cusp. They suggested that these $B_{z}$ reversals, which result from currents transverse to the field, are signatures of high-latitude FTEs. The confined current system they propose is likely to connect with temporally varying $\mathrm{C} 1 / \mathrm{C} 2$ currents such as we have discussed here.

Figure 12 shows a schematic of the coupling between the HBL and the ionosphere. A dynamo in the HBL drives a FAC pair $\mathrm{C} 1 / \mathrm{C} 2$ located poleward of the R1 current; for $B_{y}>0$ $(<0)$ the currents are prenoon (postnoon). The closure of these currents drives a flow channel in the ionosphere, which is marked with red arrows in the figure. This flow channel is distinct from the flow channel marked with black arrows, which is driven by magnetic stresses on newly opened field lines. 


\section{SuperDARN/Stokkseyri Velocity 21 Jan 2001}

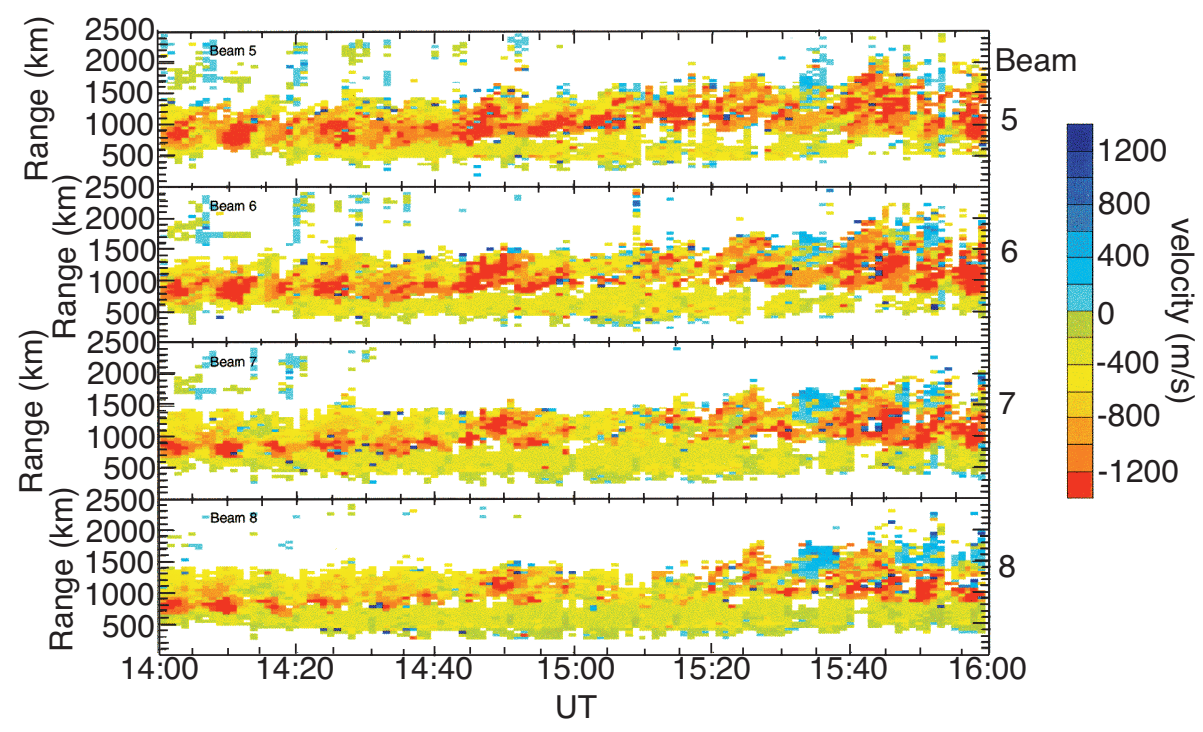

Fig. 9. Line-of-sight velocities measured in several beams of the Stokkseyri SuperDARN radar which point in the general direction of Søndrestrøm.

These observations hold important implications for extending the explanation of the Svalgaard-Mansurov effect (Svalgaard, 1968; Mansurov, 1969). The canonical explanation is that the asymmetric Maxwell stress force due to $B_{y}$ induces asymmetries in the ionospheric flow pattern on the dayside. However, it is well known (e.g. Weimer, 2001) that the asymmetry persists at least as far tailward as the terminator. A single Alfvén wave cannot account for the rotation of the magnetic field from the magnetosheath orientation to the orientation found both equatorward and poleward of the cusp, as the latter two orientations are quite different. It has long been hypothesized that a distinct Alfvén wave forms on the downstream side of the cusp (Vasyliūnas, 1995), and our observations provide support for this scenario.

The additional asymmetry due to the $\mathrm{C} 1 / \mathrm{C} 2$ FAC system may also account for differences in the propagation of prenoon and postnoon PMAFs (Sandholt and Farrugia, 2007a). These authors found that while prenoon PMAFs have a three-phase development pattern over a wide latitude range, postnoon PMAFs fade after an initial intensification and the third phase of development is not observed. Thus the dawn-dusk asymmetry of PMAFs, which manifests itself as specific high-latitude phase which is found only prenoon for $B_{y}>0$ conditions, is closely related to the convection asymmetry resulting from the additional convection channel in the same sector (Sandholt and Farrugia, 2007b).

The flow channels we report here are distinct from the reversed flow events (RFEs) which have recently been reported in radar observations from Svalbard (Oksavik et al., 2004; Rinne et al., 2007). There are several similarities between our events and RFEs, among them associations with FTEs and PMAFs and the presence of a transient flow channel. However, unlike our flow channels, the RFEs seem to have no correlation between MLT of occurrence and the sign of the IMF $B_{y}$, nor are they limited to periods with $B_{z}<0$. RFEs appear to be a manifestation of momentum transfer on newly reconnected field lines, whereas the events we describe here show that momentum transfer occurs on old open field lines.

To summarize, our contribution to the major theme of the paper, namely momentum coupling via the dynamo region in the high-latitude boundary layer (see Introduction) is as follows. Using coordinated satellite-ground observations, we documented the following elements of M-I coupling along old open field lines:

- In satellite data, we showed the presence of a specific FAC system (the C1-C2 currents) poleward of the R1 current in the prenoon (postnoon) sector for IMF $B_{y}$ positive (negative) conditions. This is identified as the HCC-LCC FACs of Taguchi et al. (1993). These currents were associated with (a) "stepped (staircase) cusp" ion precipitation: the mantle precipitation regime (Polar observations at low altitudes: $2 R_{E}$, discussed in Farrugia et al., 2004b); and (b) FTE-type, repetitive plasma injections in the $\mathrm{C} 1$ current regime (Polar observations at mid-magnetospheric altitudes: $7 R_{E}$ ).

- In ground-based data, we showed

1. Radar observations of specific flow channel (enhanced antisunward flow poleward of the convection reversal) in the prenoon (postnoon) sector for 


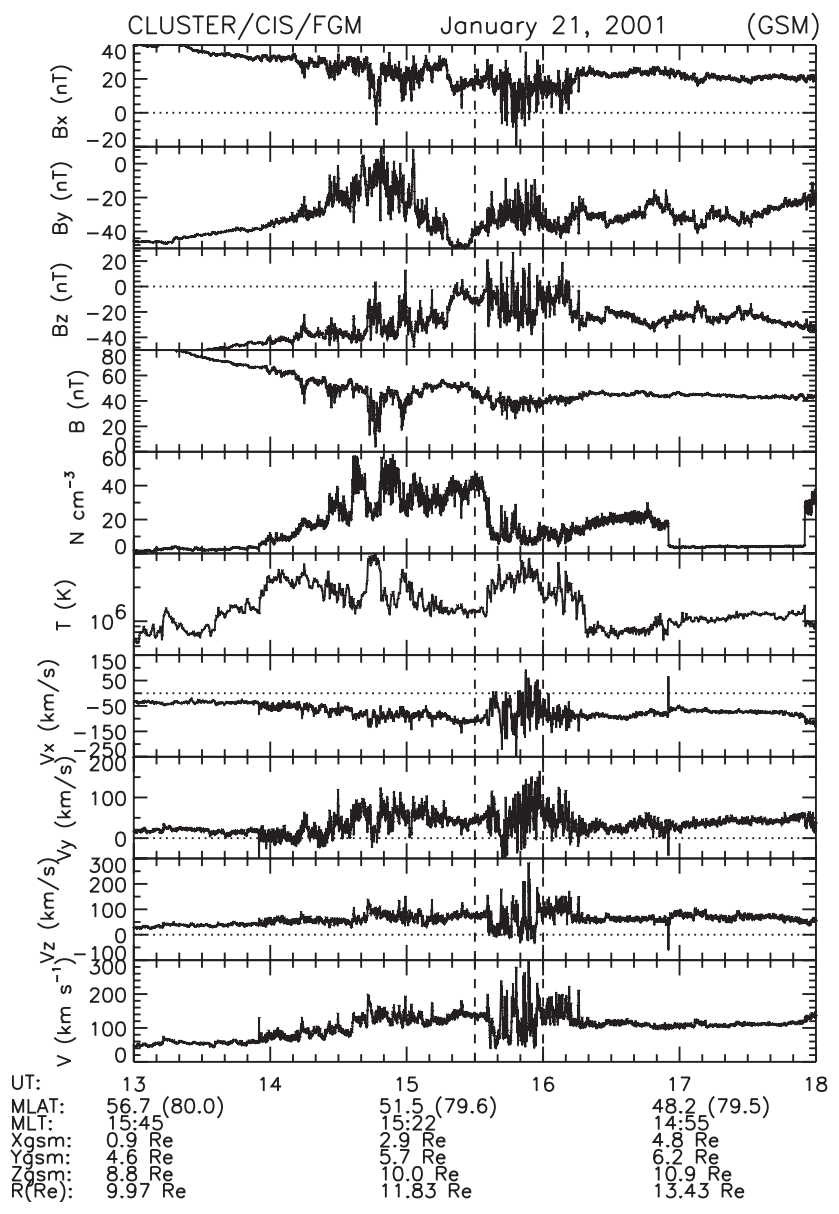

Fig. 10. Data from the Cluster traversal through the cusp. Top to bottom: Magnetic field components and magnitude; ion density, temperature, velocity components, and magnitude. The interval between vertical dashed lines is expanded in Fig. 10.

IMF $B_{y}$ positive (negative) conditions. This flow channel is the $\boldsymbol{E} \times \boldsymbol{B}$ drift associated with the Pedersen current closure of the C1-C2 FACs.

2. Relationship with poleward propagating "magnetic impulse events" appearing at lower latitudes (newly open field lines) and ending at latitudes threaded by old open field lines and mantle precipitation. The latter component is due to the Hall current associated with the above mentioned flow channel sandwiched between the $\mathrm{C} 1 / \mathrm{C} 2$ currents. This ground magnetic deflection contributes to the SvalgaardMansurov effect.

3. Relationship with the aurora in the form of the highest-latitude stage of poleward moving auroral forms (PMAFs) appearing in the prenoon (PMAFs/prenoon $/ B_{y}>0$ ) and postnoon $\left(\mathrm{PMAFs} /\right.$ postnoon $/ B_{y}<0$ ) sectors.

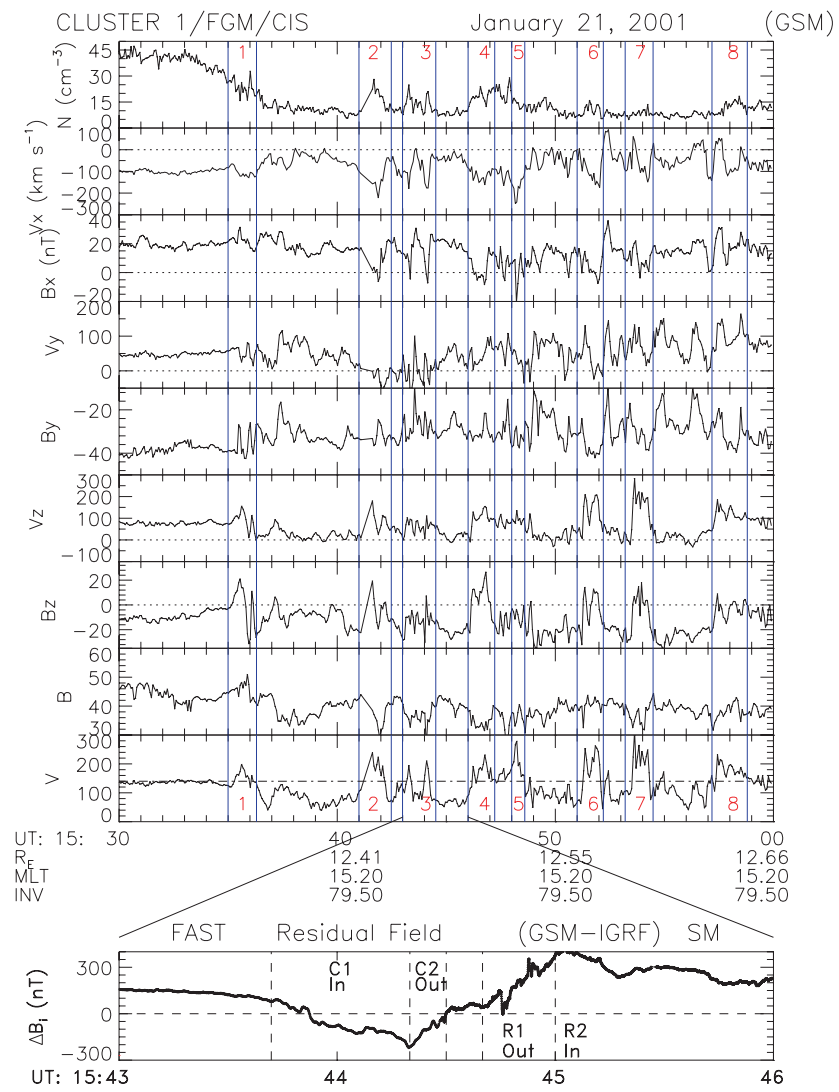

Fig. 11. Top: Expanded view of Cluster data showing density and components and magnitude of ion velocity and magnetic field. Eight flow bursts are marked in the figure. Bottom: Cross-track magnetic field (IGRF model subtracted) observed at FAST. The flow bursts are embedded in the FAC pair labeled $\mathrm{C} 1 / \mathrm{C} 2$ in the bottom panel.

\section{Conclusions}

Using magnetic conjunctions, we have investigated the implications for M-I coupling of temporal variability in the cusp/cleft $(\mathrm{C} 1 / \mathrm{C} 2)$ current system. We have shown two examples of a phenomenon wherein momentum transfer from the solar wind to the magnetosphere-ionosphere system is maintained on field lines that have reconnected some time $(\sim 10-15 \mathrm{~min})$ previously. When the IMF $\left|B_{y}\right|>\left|B_{z}\right|$, one of the asymmetries induced in the magnetosphere is a pair of field-aligned currents, located poleward of the Region 1 currents, on one side of local noon; which side depends on the sign of $B_{y}$ (Taguchi et al., 1993). Within the C1/C2 FAC pair we see many examples of Alfvénic flow bursts, which are consistent with signatures of FTEs; thus we extend the scenario of Taguchi et al. (1993) to time-varying reconnection and confirm the high-latitude FTE picture proposed by Thompson et al. (2004). The C1/C2 FACs are coupled to flow channels in the ionosphere (Farrugia et al., 2004a). The 


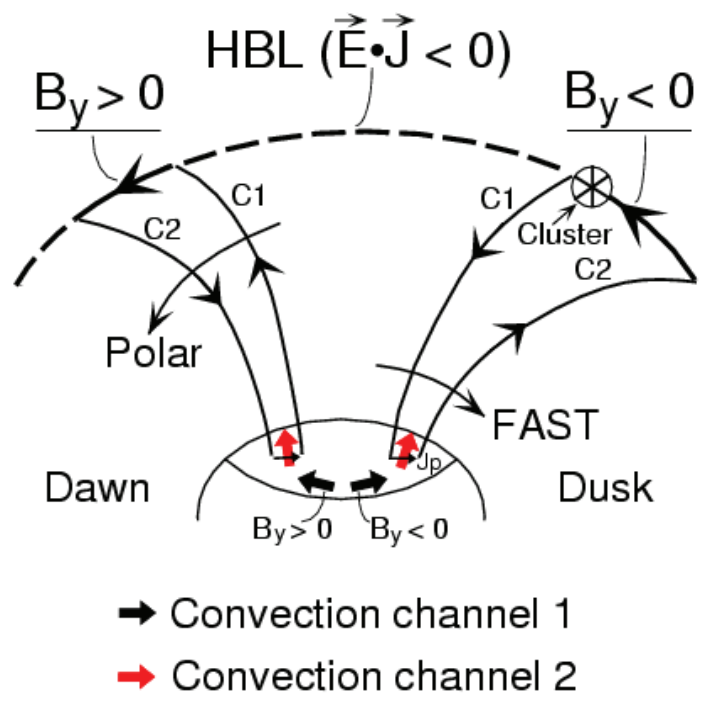

Fig. 12. Schematic of the IMF $B_{y}$-dependent FAC system located poleward of the R1 current. The red arrow marks plasma convection channels associated with the closure of the $\mathrm{C} 1 / \mathrm{C} 2$ current system. Locations of Polar during the first example and Cluster and FAST during the second example are indicated.

flow channels, in turn, are coupled to PMAFs observed in the dayside high-latitude region (Farrugia et al., 2003; Oksavik et al., 2004). By this mechanism, momentum transfer into the high-latitude ionosphere is maintained at levels significant to the dynamics of this region.

Acknowledgements. Work at the University of New Hampshire was supported by the National Aeronautics and Space Administration under grant numbers NNG05GG25G and NNX08AD11G.

Topical Editor R. Nakamura thanks three anonymous referees for their help in evaluating this paper.

\section{References}

Armstrong, J. C. and Zmuda, A. J.: Triaxial magnetic measurements of field-aligned currents at $800 \mathrm{~km}$ in the auroral region: Initial results, J. Geophys. Res., 78, 6802-6807, 1973.

Cowley, S. W. H.: Magnetospheric asymmetries associated with the $Y$-component of the IMF, Planet. Space Sci., 29, 79-86, 1981.

Cowley, S. W. H.: Magnetosphere-Ionosphere interactions: A tutorial review, in: Magnetospheric Current Systems, edited by: Ohtani, S.-I., Fujii, R., Hesse, M., and Lysak, R. L., Geophys. Monogr. Ser., vol. 118, American Geophysical Union, Washington, p. 91, 2000.

Farrugia, C. J., Sandholt, P. E., Denig, W. F., and Torbert, R. B.: Observations of a correspondence between poleward-moving auroral forms and stepped-cusp ion precipitation, J. Geophys. Res., 103, 9309-9315, 1998.

Farrugia, C. J., Sandholt, P. E., Maynard, N. C., Torbert, R. B., and Ober, D. M.: Temporal variations in a four-sheet fieldaligned current system and associated aurorae as observed during a Polar-ground magnetic conjunction in the midmorning sector, J. Geophys. Res., 108(A6), 1230, doi:10.1029/2002JA009619, 2003.

Farrugia, C. J., Lund, E. J., Sandholt, P. E., Wild, J. A., Cowley, S. W. H., Balogh, A., Mouikis, C., Möbius, E., Dunlop, M. W., Bosqued, J. M., Carlson, C. W., Parks, G. K., Cerisier, J.-C., Kelly, J. D., Sauvaud, J.-A., and Rème, H.: Pulsed flows at the high-altitude cusp poleward boundary, and associated ionospheric convection and particle signatures, during a ClusterFAST-SuperDARN-Sondrestrom conjunction under a southwest IMF, Ann. Geophys., 22, 2891-2905, 2004a, http://www.ann-geophys.net/22/2891/2004/.

Farrugia, C. J., Sandholt, P. E., Torbert, R. B., and Østgaard, N.: Temporal and spatial aspects of the cusp inferred from local and global ground- and space-based observations in a case study, J. Geophys. Res., 109, A04209, doi:10.1029/2003JA010121, 2004b.

Hovestadt, D., Hilchenbach, M., Bürgi, A., et al.: CELIAS Charge, element, and isotope analysis system for SOHO, Solar Phys., 162, 441-481, 1995.

Iijima, T., and Potemra, T. A.: Field-aligned currents in the dayside cusp observed by Triad, J. Geophys. Res., 81, 5971-5979, 1976.

Lee, L., Kan, J. R., and Akasofu, S.-I.: On the origin of cusp field aligned currents, J. Geophys., 57, 217-221, 1985.

Lepping, R. P., Acuña, M. H., Burlaga, L. F., et al.: The Wind Magnetic Field Investigation, Space Sci. Rev., 71, 207-229, 1995.

Lockwood, M. and Smith, M. F.: The variation of reconnection rate at the dayside magnetopause and cusp ion precipitation, J. Geophys. Res., 97, 14 841-14 847, 1992.

Mansurov, S. M.: New evidence of a relationship between magnetic fields in space and on Earth, Geomagn. Aeron. USSR, 9, 622 623, 1969.

Ogilvie, K. W., Chornay, D. J., Fitzenreiter, R. J., et al.: SWE, a comprehensive plasma instrument for the Wind spacecraft, Space Sci. Rev., 71, 55-77, 1995.

Øieroset, M., Sandholt, P. E., Lühr, H., Denig, W. F., and Moretto, T.: Auroral and geomagnetic events at cusp/mantle latitudes in the prenoon sector during positive IMF By conditions: Signatures of pulsed magnetopause reconnection, J. Geophys. Res., 102, 7191-7206, 1997.

Oksavik, K., Moen, J., and Carlson, H. C.: High-resolution observations of the small-scale flow pattern associated with a poleward moving auroral form in the cusp, Geophys. Res. Lett., 31, L11807, doi:10.1029/2004GL019838, 2004.

Provan, G., Milan, S. E., Lester, M., Yeoman, T. K., and Khan, H.: Simultaneous observations of the ionospheric footprint of flux transfer events and dispersed ion signatures, Ann. Geophys., 20, 281-287, 2002, http://www.ann-geophys.net/20/281/2002/.

Rinne, Y., Moen, J., Oksavik, K., and Carlson, H. C.: Reversed flow events in the winter cusp ionosphere observed by the European Incoherent Scatter (EISCAT) Svalbard radar, J. Geophys. Res., 112, A10313, doi:10.1029/2007JA012366, 2007.

Rosenbauer, H., Grünwaldt, H., Montgomery, M. D., Paschmann, G., and Sckopke, N.: HEOS 2 plasma observations in the distant polar magnetosphere: The plasma mantle, J. Geophys. Res., 80, 2723-2737, 1975.

Russell, C. T. and Elphic, R. C.: Initial ISEE magnetometer results: Magnetopause observations, Space Sci. Rev., 22, 681-715, 1978. 
Russell, C. T., Snare, R. C., Means, J. D., Pierce, D., Dearborn, D., Larson, M., Barr, G., and Le, G.: The GGS/Polar magnetic field investigation, Space Sci. Rev., 71, 563-582, 1995.

Sandholt, P. E. and Farrugia, C. J.: Role of poleward moving auroral forms in the dawn-dusk auroral precipitation asymmetries induced by IMF $B_{y}$, J. Geophys. Res., 112, A04203, doi:10.1029/2006JA011952, 2007a.

Sandholt, P. E. and Farrugia, C. J.: Poleward moving auroral forms (PMAFs) revisited: Responses of aurora, plasma convection and Birkeland currents in the pre- and postnoon sectors under positive and negative IMF $B_{y}$ conditions, Ann. Geophys., 25, 16291652, 2007b, http://www.ann-geophys.net/25/1629/2007/.

Sandholt, P. E., Farrugia, C. J., and Denig, W. F.: Detailed dayside auroral morphology as a function of local time for southeast IMF orientation: Implications for solar wind-magnetosphere coupling, Ann. Geophys., 22, 3537-3560, 2004, http://www.ann-geophys.net/22/3537/2004/.

Sandholt, P. E., Farrugia, C. J., Lund, E. J., and Denig, W. F.: IMF $B y$ and the spatio-temporal structure of the dayside aurora, in: Recurrent Magnetic Storms: Corotating Solar Wind Streams, edited by: Tsurutani, B., McPherron, R., Gonzalez, W., Lu, G., Sobral, J. H. A., and Gopalswamy, N., Geophysical Monograph 167, AGU, Washington, p. 213, 2006.

Scudder, J. D., Hunsacker, F., Miller, G., et al.: Hydra - a 3dimensional electron and ion hot plasma instrument for the Polar spacecraft, Space Sci. Rev., 71, 459-495, 1995.

Siscoe, G. L., Lotko, W., and Sonnerup, B. U. Ö.: A high-latitude, low-latitude boundary layer model of the convection current system, J. Geophys. Res., 96, 3487-3495, 1991.

Siscoe, G. L., Erickson, G. M., Sonnerup, B. U. Ö., Maynard, N. C., Siebert, K. D., Weimer, D. R., and White, W. W.: Deflected magnetosheath flow at the high-latitude magnetopause, J. Geophys. Res., 105, 12 851-12 858, 2000.

Smith, C. W., L'Heureux, J., Ness, N. F., Acuña, M. H., Burlaga, L. F., and Scheifele, J.: The ACE Magnetic Fields Experiment, Space Sci. Rev., 86, 613-632, 1998.

Smith, M. F.: Transient dayside reconnection and its effect on the ionosphere, in: Physical Signatures of Magnetospheric Boundary Layer Processes, NATO ASI Series, vol. 425, edited by: Holtet, J. A. and Egeland, A., Kluwer, Dordrecht, p. 275, 1994.

Sonnerup, B. U. Ö., Paschmann, G., Papamastoriakis, I., Sckopke, N., Haerendel, G., Bame, S. J., Asbridge, J. R., Gosling, J. T., and Russell, C. T.: Evidence for reconnection at the earth's magnetopause, J. Geophys. Res., 86, 10 049-10 067, 1981.
Southwood, D. J.: The ionopsheric signatures of flux transfer events, J. Geophys. Res., 92, 3207-3213, 1987.

Stern, D.: Magnetospheric dynamo processes, in: Magnetospheric Currents, Geophys. Monogr. Ser., vol. 28, edited by: Potemra, T., p. 200, AGU, Washington, D.C., 1984.

Svalgaard, L.: Sector structure of the interplanetary magnetic field and daily variations of the geomagnetic field at high latitudes, Geophys. Pap. R-6, Dan. Meteorol. Inst., Charlottenlund, Denmark, 1968.

Taguchi, S., Sugiura, M., Winningham, J. D., and Slavin, J. A.: Characterization of the IMF $B_{y}$-dependent field-aligned currents in the cleft region based on DE 2 observations, J. Geophys. Res., 98, 1393-1407, 1993.

Thompson, S. M., Kivelson, M. G.. Khurana, K. K.. Balogh, A., Rème, H., Fazakerley, A. N., and Kistler, L. M.: Cluster observations of quasi-periodic impulsive signatures in the dayside northern lobe: High-latitude flux transfer events, J. Geophys. Res., 109, A02213, doi:10.1029/2003JA010138, 2004.

Trattner, K. J., Fuselier, S. A., Peterson, W. K., Sauvaud, J.-A., Stenuit, H., Doubuloz, N., and Kovrazhkin, R. A.: On spatial and temporal structures in the cusp, J. Geophys. Res., 104, $28411-$ 28 421, 1999.

Tsyganenko, N. A.: A magnetospheric magnetic field model with a warped tail plasma sheet, Planet. Space Sci., 37, 5-20, 1989.

Vasyliūnas, V. M.: Multiple-branch model of the open magnetopause, Geophys. Res. Lett., 22, 1145-1147, 1995.

Weimer, D. R.: Maps of ionospheric field-aligned currents as a function of the interplanetary magnetic field derived from Dynamics Explorer 2 data, J. Geophys. Res., 106, 12 889-12 902, 2001.

Wild, J. A., Cowley, S. W. H., Davies, J. A., Khan, H., Milan, S. E., Provan, G., Yeoman, T. K., Balogh, A., Dunlop, M. W., Fornaçon, K.-H., and Georgescu, E.: First simultaneous observations of flux transfer events at the high-latitude magnetopause by the Cluster spacecraft and pulsed radar signatures in the conjugate ionosphere by the CUTLASS and EISCAT radars, Ann. Geophys., 19, 1491-1508, 2001, http://www.ann-geophys.net/19/1491/2001/.

Zmuda, A. J., Martin, J. H., and Heuring, F. T.: Transverse magnetic disturbances at $1100 \mathrm{~km}$ in the auroral region, J. Geophys. Res., 71, 5033-5045, 1966. 